\title{
Aortic complications in pregnancy: the less remembered chapter- a narrative review
}

\author{
Preetha Rajasekaran ${ }^{1}$, Praveena Gandhi ${ }^{2}$, Mohammed Idhrees ${ }^{3 *}$ (), Bashi V. Velayudhan ${ }^{3}$ (]) \\ ${ }^{1}$ Department of Obstetrics and Gynaecology, Vihaa Hospitals, Anna Nagar, Chennai 600102, India \\ ${ }^{2}$ Department of Obstetrics and Gynaecology PPN Hospital, Palani 624601, India \\ ${ }^{3}$ Institute of Cardiac and Aortic Diseases, SIMS hospital, Chennai 600026, India
}

*Correspondence: Mohammed Idhrees, Cardio Thoracic and Vascular Surgeon, Institute of Cardiac and Aortic Diseases, SRM Institutes for Medical Science (SIMS Hospitals), Chennai 600026, India. a.m.idhrees@gmail.com

Academic Editor: Kathleen Morgan, Boston University School of Medicine, USA

Received: May 26, 2021 Accepted: August 20, 2021 Published: October 31, 2021

Cite this article: Rajasekaran P, Gandhi P, Idhrees M, Velayudhan BV. Aortic complications in pregnancy: the less remembered chapter-a narrative review. Explor Med. 2021;2:423-34. https://doi.org/10.37349/emed.2021.00060

\begin{abstract}
Pregnancy increases the risk of common vascular events and also the rarer events like aortic dissection (AD)/ aortic rupture and this is even more pronounced in patients with predisposing aortopathies. AD was found to occur in $0.0004 \%$ of all pregnancies, and it is more pronounced in patients with underlying connective tissue disorders. The normal hemodynamic changes on a weak aorta will lead to AD and/or rupture, more so with increase in the period of gestation. Hence the haemodynamic and hormonal changes during pregnancy make pregnancy itself a risk factor for AD. It is advised that women with Marfan syndrome who are planning pregnancy should go through prophylactic aortic repair if the diameter of the ascending aorta exceeds $4 \mathrm{~cm}$. Pre-pregnancy counselling is very important in these patients and must include complete history taking, including family history, physical examination and advanced aortic imaging. There is a general consensus among various authors advising against surgery during pregnancy in stable patients due to increased maternal and fetal morbidity but it is justified if the condition is refractory to medical management or in life threatening stage like acute AD. Though the incidence of aortopathy in pregnancy is rare, there is a high maternal and fetal mortality associated with this condition.
\end{abstract}

\section{Keywords}

Aorta, aortic dissection, pregnancy, congenital heart disease, Marfan syndrome, Ehlers-Danlos syndrome, cardiopulmonary bypass

\section{Introduction}

Heart disease in pregnancy is the leading non-obstetric cause of maternal mortality in developing countries like India [1]. Rheumatic heart disease (RHD) is the most common cardiac disease in India unlike in developed countries where congenital heart disease (CHD) is more common. CHD is on the rise due to improving medical facilities, awareness among patients, early diagnosis and management [2]. Pregnancy increases the risk of 
common vascular events and also the rarer events like aortic dissection (AD)/aortic rupture [3] and this is even more pronounced in patients with predisposing aortopathies like heritable vascular disease, hereditary fibrillinopathies, and cono-truncal defects [4]. Though aortic dissection is not common in pregnancy, the associated mortality or morbidity when present is catastrophic.

\section{Epidemiology: how hard is the hit?}

The incidence and prevalence of heart disease during pregnancy is increasing due to the improved diagnosis and treatment coupled with the raising age of conception [5]. Heart diseases occur in $0.3-5 \%$ of pregnancies with the maternal mortality of $10-15 \%$ [5]. In a developing nation like India, 69\% of heart diseases are diagnosed during antenatal visits and another third of patients (31\%) diagnosed during labour [6]. In a ten-year study period, AD was found to occur in $0.0004 \%$ of all pregnancies [7]. AD occurs more commonly in patients with underlying connective tissue disorders, Marfan syndrome (MFS) being the commonest [8]. The maternal mortality is higher in patients with Stanford type A AD. Patients with aortopathy are more likely to undergo an emergency caesarean section (CS) as compared to the general population (16\% versus $3 \%$ ). Further these patients have higher incidence of postpartum haemorrhage (PPH) [4]. There is a four-fold increase in fetal mortality rate and a higher rate of preterm delivery in patients with heart diseases [9].

\section{Knowing the normal}

\section{Hemodynamic changes}

The changes include an increase in cardiac output (maximum in third trimester), stroke volume, heart rate (by 10-20 beats/min), left ventricular mass, plasma volume (40\%), and red blood cell mass (20\%) [10]. Increased aortic compliance leads to decrease in vascular resistance and cardiac after load, and an increase in left ventricular performance, while the blood pressure is maintained. These normal physiological changes weaken a diseased aorta leading to $\mathrm{AD}$ and/or rupture, more so with increase in period of gestation [11-13]. The gravid uterus which may compress the abdominal aorta and iliac arteries increases the resistance of lower arterial tree which eventually increases the afterload of the heart [11-13]. This in turn increases the afterload on the heart leading to intimal tear [13]. In case of obstructive lesions like coarctation of aorta and stenotic valvular lesion, the gradient across the coarctation and the transvalvular gradient are increased respectively [11-15].

\section{Hormonal changes}

The hormonal effects on aorta are predominantly due to estrogen and to certain extent due to progesterone. Estradiol binds to the high affinity estrogen receptor present on the aortic tissue and alter the collagen biosynthesis in the aortic smooth muscle cells [11]. Estrogen increases the release of matrix metalloproteinases (MMP-2) which alters the lumen diameter and compliance [16]. The changes which occur in the medial layer of the aorta are smooth muscle hyperplasia or hypertrophy, fragmentation of the reticulin fibers, and disorganization of the elastic layer [15].

\section{Thromboembolic}

There is an increase in coagulation factors, fibrinogen and plasminogen activators and inhibitors of fibrinolysis. As the age of conception is on the rise, there may also be age related changes like cystic medial necrosis which are further worsened by hypertension [13].

\section{Aortopathy in pregnancy}

\section{Bicuspid aortic valve}

In women of reproductive age group, the main cause of aortic stenosis is congenital bicuspid aortic valve (BAV) which affects about $1 \%$ of the population [17] wherein there is partial or complete fusion of the aortic valve commissures. BAV is present in $25-50 \%$ of patients with coarctation of aorta [18]. Almost $50 \%$ of patients with BAV and aortic stenosis have dilatation of the ascending aorta [19]. Hence AD is a possibility, though less 
frequent than in MFS [14]. Patients with BAV and significant aortopathy (aortic root dilatation of more than $45 \mathrm{~mm}$ ) should be counselling not to become pregnant. Surgery for aorta is recommended in patients with aortic root dilatation of more than $50 \mathrm{~mm}$ [20].

\section{Marfan syndrome}

Marfan syndrome, caused by a mutation in the FBN1 gene, involves multiple organ systems and diagnosis is based on Ghent criteria [21]. FBN1 gene is on chromosome 15q21 encoding for fibrillin 1, a glycoprotein found in microfibrils of elastic fiber. Over 600 mutations have been described in FBN1 gene. Usually patients are tall in stature, with kyphoscoliosis, elongated fingers and toes and have pectus deformities. Ocular manifestations may vary from high myopia, ectopic lentis, and lens dislocation. Cardiovascular features are aortic root aneurysm, aortic dissection, and primary mitral valve prolapse with or without regurgitation [22]. Most of them present with a dilation of the aortic root or ascending aorta or aortic dissection. When the aortic diameter is larger than $40 \mathrm{~mm}$, measured on the sinus of Valsalva sinuses, thoracic aortic aneurysm is considered to exist in these patients [23].

\section{Ehlers-Danlos syndrome}

Vascular Ehlers-Danlos syndrome is a rare, high-risk, heritable connective tissue disorder which is characterized by friable connective tissues, which can cause rupture of blood vessels or other internal organs, like uterus or intestines [24]. As there is a risk of uterine rupture, vascular Ehlers-Danlos syndrome is a contra-indication for pregnancy. AD in these patients may occur without dilatation of the aorta [25]. Women with Ehlers-Danlos type IV have an increased risk of complications in pregnancy and $50 \%$ risk of having an affected child. There is no proven treatment to prevent acute arterial events for patients with Ehlers-Danlos syndrome.

\section{Turner syndrome}

It is a rare genetic disorder that occurs when all or part of one of the two $\mathrm{X}$ chromosomes in the developing embryo is lost. Those with $45 \mathrm{X} 0$ chromosomes require oocyte donation and in vitro fertilization to conceive [26]. It is associated with risk of aortic root dilatation or aortic dissection. AD may occur even if there is no dilatation of the aorta [27]. These patients must undergo complete cardiac assessment prior to pregnancy. Deaths and severe morbidity during pregnancy and peripartum period are described in patients with Turner syndrome, due to acute $\mathrm{AD}$. This risk of $\mathrm{AD}$ is evaluated to be $2 \%$, with an increased risk of maternal death as much as 100-fold during pregnancy [28].

\section{Loeys-Dietz syndrome}

Loeys-Dietz syndrome is an autosomal dominant disorder that arises due to defects in TGF-beta receptors (TGF BR1 and TGF BR2). This syndrome is characterized by arterial tortuosity, ascending aortic aneurysm and AD. Unlike MFS, Loeys-Dietz syndrome has increased risk, where aneurysm can occur anywhere in the arterial system. These aneurysms tend to rupture at an earlier stage and size [29]. Obstetric complication can be preterm premature rupture of membranes, bowel rupture, uterine rupture, rupture of blood vessels during labour. A recent report of 85 patients with 217 pregnancies reported $3(1 \%)$ maternal deaths and $15(7 \%)$ severe complications (including aortic and vertebral artery dissection) [30].

\section{Risk stratification}

The haemodynamic and hormonal changes during pregnancy make pregnancy itself a risk factor for AD [31]. Higher birth order and third trimester or peripartum period of pregnancy carry an increased risk. Uncontrolled hypertension during pregnancy is an independent risk factor for AD [32]. Other risk factors include a family history, previous history of dissection, smoking, aortic size and rapid growth [33].

The risk stratification by World Health Organization (Table 1) is commonly used for assessing cardiovascular risk in pregnant women [34]. According to this classification, pregnancy is contraindicated when the aorta diameter of more than $45 \mathrm{~mm}$ in patients with MFS, and more than $50 \mathrm{~mm}$ in BAV. Other 
contraindications include Ehlers-Danlos syndrome type IV and patients with a past history of type B AD according to European Society of Cardiology (ESC) guidelines of 2011 [20].

Table 1. Modified WHO classification of maternal cardiovascular risk: application

WHO II-III (depending on individual)-Small increased risk of maternal mortality or moderate increase in morbidity.

- Marfan syndrome without aortic dilatation

- Aorta $<45 \mathrm{~mm}$ in aortic disease associated with bicuspid aortic valve

- Repaired coarctation

WHO III-Significantly increased risk of maternal mortality or severe morbidity. Expert counselling required. If pregnancy is decided upon, intensive specialist cardiac and obstetric monitoring needed throughout pregnancy, childbirth, and the puerperium.

- Aortic dilatation 40-45 mm in Marfan syndrome

- Aortic dilatation 45-50 mm in aortic disease associated with bicuspid aortic valve

WHO IV-Extremely high risk of maternal mortality or severe morbidity; pregnancy contraindicated. If pregnancy occurs termination should be discussed. If pregnancy continues, care as for class III.

- Severe systemic ventricular dysfunction (LVEF $<30 \%$, NYHA III-IV)

- Marfan syndrome with aorta dilated $>45 \mathrm{~mm}$

- Aortic dilatation $>50 \mathrm{~mm}$ in aortic disease associated with bicuspid aortic valve

- Native severe coarctation

LVEF: left ventricular ejection fraction; NYHA: New York Heart Association; WHO: World Health Organization

Rajagopalan et al. [8] conducted an outcome analysis in pregnant women with acute AD, which showed that half of these women (49\%) had a systemic disease, with MFS being the most common (41\%). Patients with an aortic root diameter below $40 \mathrm{~mm}$ have a low risk of AD [35]. Pre-pregnancy surgery is recommended when the ascending aorta is $45 \mathrm{~mm}$. Surgical intervention should be considered prior to pregnancy in patients at risk of AD or rupture. The 2010 American College of Cardiology | American Association of Thoracic Surgeons | American Heart Association (ACC | AATS | AHA) guidelines advise prophylactic aortic repair in women planning pregnancy if the diameter of the ascending aorta exceeds $4 \mathrm{~cm}$ in patients with MFS (Table 2) [36].

Table 2. Thresholds for elective surgical intervention prior to pregnancy and indication for caesarean section [35]

\begin{tabular}{lll}
\hline Disease & Indication prepregnant surgery & Indication caesarean section \\
\hline Marfan syndrome & $\geq 45 \mathrm{~mm}$ & $\geq 45 \mathrm{~mm}$ \\
Turner syndrome & $\geq 27 \mathrm{~mm} / \mathrm{m}^{2}$ & $\geq 27 \mathrm{~mm} / \mathrm{m}^{2}$ \\
Bicuspid aortic valve & $\geq 50 \mathrm{~mm}$ & $\geq 45 \mathrm{~mm}$ \\
Loeys-Dietz syndrome & $\geq 45 \mathrm{~mm}$ & $\geq 45 \mathrm{~mm}$ \\
Vascular Ehlers-Danlos Syndrome & Contraindicated & Always \\
Others & $\geq 50 \mathrm{~mm}$ & $\geq 45 \mathrm{~mm}$ \\
\hline
\end{tabular}

In patients with Turner syndrome, an aortic size index greater than or equal to $2.5 \mathrm{~cm} / \mathrm{m}^{2}$ are at highest risk for $\mathrm{AD}$ [37]. Pre-pregnancy prophylactic surgery should be considered in patients with an aortic size index of at least $2.7 \mathrm{~cm} / \mathrm{m}^{2}$ [20]. BAV is an independent risk factor for AD. Pre-pregnancy prophylactic surgery is recommended in patients with an aortic root diameter of more than $50 \mathrm{~mm}$ [14]. In patients with Loeys-Dietz syndrome, one of the studies is a review of 52 probands with 21 pregnancies in 12 women, AD was present in four women during pregnancy or postpartum [38]. Patients with vascular Ehlers-Danlos syndrome have a high risk of uterine rupture. They also have a high risk of AD or rupture of aneurysm, more commonly during delivery or postpartum. Hence vascular Ehlers-Danlos syndrome is a contraindication for pregnancy [24].

\section{Pre-conception counselling: unfurl the umbrella before getting fully drenched}

Pre-pregnancy counselling is very important and must include complete history taking, including family history, physical examination and advanced aortic imaging. Magnetic resonance imaging or computed tomography has to be done and both aortic root diameter and growth rate must be followed. A multi-disciplinary team 
involving a cardiologist, cardiac surgeon, obstetrician and anaesthetist must be involved. Patients should be discussed regarding the absolute contra-indications to pregnancy, timing of pre-pregnancy surgery, maternal and fetal risks, obstetric complications that may arise and their management plan, genetic counselling for hereditary conditions like MFS and the choices of available safe contraception. Pregnancy must be discouraged when the risk of maternal death is more than $10 \%$ as in patients with MFS with a dilated aortic root of more than $4 \mathrm{~cm}$ and aortic dilation of more than $5 \mathrm{~cm}$ in patients with BAV [39].

The considerations prior to conception include (a) maternal risk stratification (b) functional capacity determination (c) echocardiography (d) cardio pulmonary exercise testing (e) cardiac magnetic resonance imaging (f) cardiac medication review (g) control co-morbidities like hypertension, diabetes and obesity (h) surgical intervention (i) genetic counselling. Genetic counselling must be offered to women with hereditary disorders. In patients having autosomal dominant disorders, the risk of having an affected child is about $50 \%$. Recently pre- implantation genetic diagnosis before pregnancy has been introduced and must be made avail for the patients when appropriate [40].

Proper contraception advice should be given to women who do not wish to conceive. Combined oral contraceptive pills are usually contraindicated in women with hypertension and those at risk of thromboembolism. Intrauterine devices are associated with a risk of bacteraemia. Progesterone preparations are safe in women with heart disease. Surrogacy and adoption may be the safest in women with fatal risks.

Though robust data lack, whole exome genetic sequencing can be advised for pregnant women who present with aneurysm or AD. Prenatal Whole exome genetic sequencing also has a role in women where a fetus has structural abnormalities with reported consanguinity or homozygosity indicative of relatedness on microarray. American College of Medical Genetics and Genomics and the Society of Maternal Fetal Medicine recommend that all patients considering Whole exome sequencing (WES) receive counselling from a provider with genetics expertise [41].

\section{Management of pregnancy: act if you can, when you can}

Patients with any aortic pathology must be carefully monitored by echocardiographyat 4-12 weekly intervals throughout pregnancy and till 6 months postpartum period [20].

The guidelines at each trimester include:

1) First trimester:

a) multidisciplinary team approach-include cardiologist, cardiac surgeon, fetal medicine expert, obstetric anesthetist, obstetrician and neonatologist;

b) maternal Cardiac evaluation: echocardiography every 4-12 weeks;

c) anti-hypertensive therapy;

d) aspirin if indicated;

e) anticoagulation adjustment;

f) genetic counselling if needed.

2) Second trimester:

a) fetal echocardiogram at 18-22 weeks;

b) genetic evaluation, if needed amniocentesis.

3) Third trimester:

a) maternal cardiac evaluation;

b) echocardiography at 30 weeks;

c) fetal growth surveillance;

d) fetal testing-modified biophysical profile testing by non-stress test and amniotic fluid volume. 
4) Postpartum:

In the postpartum period careful monitoring of the patient by the multidisciplinary team comprising of the cardiac surgeon, obstetrician, anaesthetist and cardiologist is of paramount importance. Contraception advice must also be given in the postpartum period [42].

Medical therapy:

Medical treatment aims to maintain blood pressure in normal range with appropriate anti- hypertensive treatment, optimal lipid control. Advice on smoking cessation and obesity management has to be given [34]. For patients with known thoracic aortic dilatation or a genetic predisposition for aortic dissection, strict blood pressure control is recommended, to prevent stage II hypertension [36]. Angiotensin receptor blocker and angiotensin converting enzyme inhibitors are contraindicated during pregnancy, because of teratogenic effects.

Beta-blockers may reduce the risk of aortic dissection in patients with MFS [43]. Beta- blockers decrease the impact force of ejected blood on the aorta, decrease heart rate as well as the blood pressure. In a 10-year study of beta-blockers in MFS, patients treated with propranolol, had a lower rate of aortic root dilatation and fewer cardiovascular endpoint (defined as aortic regurgitation, dissection, surgery, heart failure or deaths), and improved survival than untreated patients [44].

In women with MFS, frequent monitoring of cardiac parameter is needed. An echocardiogram must be taken at the time of diagnosis to determine aortic root and ascending aortic diameter [36]. Evaluation of aortic root diameter in early postpartum period is also necessary [45]. Prophylactic surgery may be considered in patients with progressive aortic root dilatation and/or advancing aortic valve regurgitation [42]. Lind [46] reported 117 pregnancies complicated by 5 ADs.

\section{Timing of aortic surgery in pregnancy}

There is a general consensus among various authors advising against surgery during pregnancy in stable patients due to increased maternal and fetal morbidity (3-6\%) and mortality (3\%) [47]. Surgery is justified when the condition is refractory to medical management or in life threatening stage like acute AD. In type B aortic dissection, thoracic endovascular aortic repair (TEVAR) can be performed, if medical management fails $[6,17]$.

The following principles have to be followed when surgery is considered:

1) avoid surgery in first trimester when the fetal organogenesis happens;

2) optimize the uteroplacental perfusion strategies when surgery is required;

3) continue fetal and uteroplacental monitoring and adjust the cardiopulmonary bypass (CPB) strategy to avoid any hypoperfusion or fetal bradycardia;

4) avoid vasopressors as it may constrict the placental vessels [47].

The timing of elective surgery depends on the period of gestation and the viability of the fetus while emergency surgery is performed irrespective of the gestational age or fetal viability. Though surgery in first trimester is safe for the mother, but it carries a higher incidence of malformations and demise.

Second trimester is considered as a safe period for cardiac surgery during pregnancy. During this period, the fetal organogenesis is near completion and hemodynamic changes of the mother are not at its peak. During late second trimester, the cut-off differs with different neonatal units $(<24$ or $<28$ weeks) $[3,8]$.

When the period of gestation is between 28-32 weeks, the decision should be made based on the fetal viability. Steroid prophylaxis for lung maturity should be considered when the fetus is viable.

When the gestation is more than 32 weeks, caesarean section followed by aortic repair is the proposed line of management by most centres $[8,9]$. Aortic surgery should be planned well in advance before labour sets in, as aortic dissection or rupture occurs in the postpartum period carrying a high maternal mortality rate due to the peak hemodynamic changes. Few surgeons have performed aortic repair after caesarean section [14]. 
The rationale for CS followed by aortic repair includes:

1) Anaesthesia, smooth muscle relaxation, hypothermia, anti-coagulation lead to haemorrhage and cause severe morbidity and mortality;

2) During CPB though certain variables are favourable for the mother, many have an adverse effect on the fetus. a) Hypothermia leads to impaired uteroplacental perfusion and uterine contractions culminating in fetal bradycardia and demise b) longer period of deep hypothermic circulatory arrest may lead to fetal loss c) cardioplegic arrest with hyperkalemia leads to fetal bradycardia eventually leading to fetal distress and loss $[13,14]$.

Risk of preterm labor was high in third trimester surgeries but lesser fetal mortality when compared to first or second trimester surgeries [48].

The following perfusion strategy should be followed $[7,14]$ :

1) normothermia is preferred, if hypothermia is mandatory, moderate hypothermia (28 degree C) is preferred and antegrade cerebral perfusion is used;

2) a high flow rate of more than $2.4 \mathrm{~L} / \mathrm{min} / \mathrm{m}^{2}$ is used;

3) a mean arterial pressure of more than $70 \mathrm{mmHg}$ is maintained. When there is a fall in pressure increase the pump flow and avoid using vasopressor;

4) cold blood cardioplegia;

5) maintain a pulsatile flow (which causes release of endothelial derived vasodilators).

In spite of all these strategies the post-operative mortality and morbidity are high in emergency surgeries. The maternal mortality rate at one month was $40-50 \%$ and the patients who survived have a higher morbidity which included renal failure, respiratory compromise and neurologic damage [49].

\section{Acute aortic syndrome in pregnancy}

$\mathrm{AD}$ and aortic rupture are not common yet they are life threatening conditions, that carry a high maternal and fetal mortality. It commonly occurs in those with connective tissue disorders like MFS, Ehlers-Danlos syndrome, Turner syndrome and in patients with BAV.

Sometimes aortic complications can also occur in women without any risk factors [48]. AD in pregnancy is more prone to occur in third trimester and postpartum because of the hormonal changes and haemodynamic effects [50]. Acute AD usually presents with sudden, severe, tearing chest pain, vomiting and syncope, most often from acute pericordial tamponade.

Emergency physicians must have the knowledge and skill to identify dissection and call for the multidisciplinary team to resuscitate pregnant patients who present to the emergency room with symptoms suggestive of AD. Transesophageal echocardiography can be used for diagnosis when facilities and expertise are available [20]. Since transesophageal echocardiography is not readily available, bedside ultrasound may be handy. Visualization of pericardial effusion on ultrasound has a high specificity [49]. Electrocardiogram may be normal or show signs of left ventricular hypertrophy or acute myocardial infarction if the coronary arteries are involved. Changes in chest $\mathrm{x}$-ray are seen only in $85 \%$ of the patients.

For acute type A AD occurring during first or second trimester, urgent surgical repair is preferred. The fetus has to be carefully monitored in such cases, as fetal death during CPB is common. The overall maternal mortality during the procedure is around $5 \%$ and fetal and neonatal mortality is about 15 to $30 \%$.

Ch'ng et al. [51] reported that of the aortic dissections occurring in women ( $n=73)$, five occurred in pregnant women. Four women were at gestational age of more than 32 weeks, for whom aortic repair followed the caesarean section was performed. Nevertheless, the best survival chance to the fetus will be there in cases where caesarean section is followed by surgical repair.

In type B aortic dissection, medical treatment is preferred. In case of aortic rupture or subacute aortic leaking, TEVAR can be performed [52]. 


\section{Management during labour}

The primary aim during labour is to avoid excess cardiovascular stress by monitoring the maternal heart rate, blood pressure, saturation and electrocardiogram. Labour analgesia helps in reducing catecholamine surges associated with labour pain. Continuous lumbar epidural may be used [20]. Uterine contraction pushes around 300-500 mL of venous blood to central venous system. Pain, anxiety, position, bleeding, uterine involution, raised blood pressure, heart rate in second stage and diversion of around $500 \mathrm{~mL}$ of blood from uteroplacental bed to the maternal circulation all these pose high risk [53].

A maternal hematocrit of more than $28 \%$ is preferred. In low risk cases where vaginal delivery has been decided as the mode of delivery, wait for spontaneous onset of labour based on the cardiac status, Bishop score, fetal well-being and lung maturity. If induction is required mechanical dilatation (Foley) is preferred, prostaglandin E2 gel can also be used [20]. Unlike developed nations, anti-bacterial endocarditis prophylaxis is preferred for all Indian patients with heart disease [6].

The patient is placed in left lateral decubitus position to increase the hemodynamic impact of uterine contractions so as to bring the fetal head to the perineum without maternal pushing. Continuous fetal monitoring with cardiotocography is mandatory. The second stage is cut short using low forceps or vacuum. Injection oxytocin is used after the second stage except in heart failure patients. In case of elective CS fetal lung maturity is obtained with steroid prophylaxis and CS is performed before labour sets in, to avoid blood pressure and cardiac output variations. Depending upon the clinical situation, either regional or general anesthesia is used with the patient being positioned to maintain the uterine displacement avoiding aortocaval compression. To avoid postpartum hemorrage, intrauterine placement of Cook balloon [7] and B-Lynch [3] were tried by different authors. It is not advisable to use anti fibrinolytics like tranexemic acid [36].

\section{Postpartum management}

The highest risk periods for aortopathy patients are the third trimester and the postpartum period. Extreme caution and close monitoring are needed to avoid any untoward happenings, as hemodynamic changes are maximum during this period. After the placental delivery, uteroplacental blood gets diverted to the maternal circulation affecting the cardiac output which in turn affects the aortic vasculature and increased risk of dissection. Oxytocin infusion less than 2 units/min, prostaglandin F (carboprost) can be used to achieve hemostasis, while methylergometrin is contraindicated in these patients [20].

Patients with aortopathies have to be observed for a period of 1-2 weeks in hospital to detect new pathological changes in aorta [53]. Leg exercises, stockings, ambulation should be advised for these patients. Though studies have shown that pregnancy changes revert back to pre- pregnant state after 6 weeks in most patients, the aortic diameter remains larger than the pre-pregnant state [20]. Beta-blockers are used up to 3-6 months to maintain optimal blood pressure due to the risk of AD during this period. Imaging of the aorta with echocardiography, computer tomography, magnetic resonance imaging at regular intervals based on the individual risk factors, size of the aorta, location of the dilatation. The patient has to be advised that there is increased risk of AD in her immediate family. The patients who had AD without any underlying risk factors should undergo genetic screening [16]. New-borns of mothers with CHD should undergo complete cardiac evaluation, since the risk of inheritance is $3-5 \%$ when compared to $1 \%$ in general population [6]. Fetal growth restriction and low birth weight are known complications of aortopathy in pregnancy. Mothers should be made aware of the risk of cardiovascular diseases and metabolic syndrome in later part of life [10].

\section{Conclusions}

Though the incidence of aortopathy in pregnancy is rare, there is a high maternal and fetal mortality associated with this condition. This makes it criterion to address the issue. Identifying patients prior to conception is very important. Pre-pregnancy counselling must be given considering the heritable nature of many associated diseases and appropriate genetic counselling must be given. For patients with absolute 
contra-indications to become pregnant, contraceptive advice, and other available options like surrogacy or adoption must be discussed.

As pregnancy itself can worsen the disease, due to the hormonal and vascular effects, a multi- disciplinary team including obstetrician, obstetric anaesthetist, cardiologist, cardio thoracic surgeon, fetal medicine expert and neonatologist must be involved in planning the pregnancy management, timing elective aortic surgery if needed, considering the best options for safe delivery and in dealing with emergency aortic dissection and neonatal management. Emergency physician must be well trained to diagnose and resuscitate pregnant patients with acute aortic syndrome which can later be managed by surgery or medical means depending on the type of aortic dissection. By following frequent cardiac evaluation, planned elective aortic surgeries, good antenatal management strategies, timing delivery at right time and with neonatal support, we can attempt to prevent maternal and neonatal death due to aortopathy in pregnancy.

\section{Abbreviations}

AD: aortic dissection

BAV: bicuspid aortic valve

CHD: congenital heart disease

CPB: cardiopulmonary bypass

CS: caesarean section

MFS: Marfan syndrome

WHO: World Health Organization

\section{Declarations}

\section{Author contributions}

MI contributed to the conception and design of the study; PR wrote the following sections: Aortopathy in pregnancy, Risk stratification, Pre-conception counselling, Management of pregnancy, Acute aortic syndrome in pregnancy, Conclusions; PG wrote the physiological effect of pregnancy on aorta and the following sections: Introduction, Epidemiology, Timing of aortic surgery in pregnancy, Management during labour, Postpartum management. MI and BV provided overall supervision for this study. All authors contributed to manuscript review, and read and approved the submitted version.

\section{Conflicts of interest}

The authors declare that they have no conflicts of interest.

\section{Ethical approval}

Not applicable.

\section{Consent to participate}

Not applicable.

\section{Consent to publication}

Not applicable.

\section{Availability of data and materials}

Not applicable.

\section{Funding}

Not applicable. 


\section{Copyright}

(C) The Author(s) 2021.

\section{References}

1. Paily VP, Ambujam K, Rajasekharan Nair V, Thomas B. Confidential review of maternal deaths in Kerala: a country case study. BJOG. 2014;121 Suppl 4:61-6.

2. Khan DA, Sharma N, Kapoor M, Duwarah SG, Ahanthem SS. The spectrum of heart disease in pregnancy and its outcome in patients visiting a tertiary care centre of Northeastern: a prospective study. J Clin Diagn Res. 2018;12:16-20.

3. Patel PV, Alter R, Frenn R, Waters TP. Aortic dissection in a pregnant patient without other risk factors. Case Rep Obstet Gynecol. 2019;2019:1583509.

4. Bradley EA, Zaidi AN, Goldsmith P, Sisk T, Colombo D, Roble S, etal. Major adverse maternal cardiovascular-related events in those with aortopathies. What should we expect? Int J Cardiol. 2014;177:229-34.

5. Agrawal S, Agrawal A, Bhandari M, Siddiqui SS, Koonwar S. Critical analysis of all pregnancies with heart disease, misses and near misses over 1-year period along with expert group so as to optimize outcome and improve patient care - need-based analysis. Heart India. 2019;7:55-62.

6. Konar H, Chaudhuri S. Pregnancy complicated by maternal heart disease: a review of 281 women. J Obstet Gynaecol India. 2012;62:301-6.

7. Zhu JM, Ma WG, Peterss S, Wang LF, Qiao ZY, Ziganshin BA, et al. Aortic dissection in pregnancy: management strategy and outcomes. Ann Thorac Surg. 2017;103:1199-206.

8. Rajagopalan S, Nwazota N, Chandrasekhar S. Outcomes in pregnant women with acute aortic dissections: a review of the literature from 2003 to 2013. Int J Obstet Anesth. 2014;23:348-56.

9. John AS, Gurley F, Schaff HV, Warnes CA, Phillips SD, Arendt KW, et al. Cardiopulmonary bypass during pregnancy. Ann Thorac Surg. 2011;91:1191-6.

10. Nguyen Manh T, Bui Van N, Le Thi H, Vo Hoang L, Nguyen Si Anh H, Trinh Thi Thu H, et al. Pregnancy with heart disease: maternal outcomes and risk factors for fetal growth restriction. Int J Environ Res Public Health. 2019;16:2075.

11. Hart MV, Morton MJ, Hosenpud JD, Metcalfe J. Aortic function during normal human pregnancy. Am J Obstet Gynecol. 1986;154:887-91.

12. Bons LR, Roos-Hesselink JW. Aortic disease and pregnancy. Curr Opin Cardiol. 2016;31:611-7.

13. Nolte JE, Rutherford RB, Nawaz S, Rosenberger A, Speers WC, Krupski WC. Arterial dissections associated with pregnancy. J Vasc Surg. 1995;21:515-20.

14. Immer FF, Bansi AG, Immer-Bansi AS, McDougall J, Zehr KJ, Schaff HV, et al. Aortic dissection in pregnancy: analysis of risk factors and outcome. Ann Thorac Surg. 2003;76:309-14.

15. van Hagen IM, Roos-Hesselink JW. Aorta pathology and pregnancy. Best Pract Res Clin Obstet Gynaecol. 2014;28:537-50.

16. Goland S, Elkayam U. Cardiovascular problems in pregnant women with Marfan syndrome. Circulation. 2009;119:619-23.

17. Pearson GD, Devereux R, Loeys B, Maslen C, Milewicz D, Pyeritz R, et al; National Heart, Lung, and Blood Institute and National Marfan Foundation Working Group. Report of the National Heart, Lung, and Blood Institute and National Marfan Foundation Working Group on research in Marfan syndrome and related disorders. Circulation. 2008;118:785-91.

18. Roos-Hesselink JW, Schölzel BE, Heijdra RJ, Spitaels SE, Meijboom FJ, Boersma E, et al. Aortic valve and aortic arch pathology after coarctation repair. Heart. 2003;89:1074-7. 
19. Fedak PW, de Sa MP, Verma S, Nili N, Kazemian P, Butany J, et al. Vascular matrix remodeling in patients with bicuspid aortic valve malformations: implications for aortic dilatation. J Thorac Cardiovasc Surg. 2003;126:797-806.

20. European Society of Gynecology (ESG); Association for European Paediatric Cardiology (AEPC); German Society for Gender Medicine (DGesGM); Regitz-Zagrosek V, Blomstrom Lundqvist C, Borghi C, Cifkova R, Ferreira R, Foidart JM, et al; ESC Committee for Practice Guidelines. ESC Guidelines on the management of cardiovascular diseases during pregnancy: the task force on the management of cardiovascular diseases during pregnancy of the European Society of Cardiology (ESC). Eur Heart J. 2011;32:3147-97.

21. De Paepe A, Devereux RB, Dietz HC, Hennekam RC, Pyeritz RE. Revised diagnostic criteria for the Marfan syndrome. Am J Med Genet. 1996;62:417-26.

22. Levenson D. New guidelines for diagnosis of Marfan and Loey-Dietz syndromes. Am J Med Genet A. 2010;152A:fmvii-viii.

23. Roman MJ, Devereux RB, Kramer-Fox R, O'Loughlin J. Two-dimensional echocardiographic aortic root dimensions in normal children and adults. Am J Cardiol. 1989;64:507-12.

24. Pepin M, Schwarze U, Superti-Furga A, Byers PH. Clinical and genetic features of Ehlers- Danlos syndrome type IV, the vascular type. N Engl J Med. 2000;342:673-80.

25. Coulon C. Thoracic aortic aneurysms and pregnancy. Presse Med. 2015;44:1126-35.

26. Church E, Bellis A, O'Connell I, Naqvi N. Successful pregnancy outcome in a woman with Turner's syndrome. Obstet Med. 2014;7:126-7.

27. Karnis MF. Catastrophic consequences of assisted reproduction: the case of Turner syndrome. Semin Reprod Med. 2012;30:116-22.

28. Karnis MF, Zimon AE, Lalwani SI, Timmreck LS, Klipstein S, Reindollar RH. Risk of death in pregnancy achieved through oocyte donation in patients with Turner syndrome: a national survey. Fertil Steril. 2003;80:498-501.

29. Loeys BL, Chen J, Neptune ER, Judge DP, Podowski M, Holm T, et al. A syndrome of altered cardiovascular, craniofacial, neurocognitive and skeletal development caused by mutations in TGFBR1 or TGFBR2. Nat Genet. 2005;37:275-81.

30. Frise CJ, Pitcher A, Mackillop L. Loeys-Dietz syndrome and pregnancy: the first ten years. Int J Cardiol. 2017;226:21-5.

31. Nasiell J, Lindqvist PG. Aortic dissection in pregnancy: the incidence of a life-threatening disease. Eur J Obstet Gynecol Reprod Biol. 2010;149:120-1.

32. Coady MA, Davies RR, Roberts M, Goldstein LJ, Rogalski MJ, Rizzo JA, et al. Familiar patterns of thoracic aortic aneurysms. Arch Surg.1999;134:361-7.

33. Erbel R, Eggebrecht H. Aortic dimensions and the risk of dissection. Heart. 2006;92:137-42.

34. Thorne S, Nelson-Piercy C, MacGregor A, Gibbs S, Crowhurst J, Panay N, et al. Pregnancy and contraception in heart disease and pulmonary arterial hypertension. J Fam Plann Reprod Health Care. 2006;32:75-81.

35. Donnelly RT, Pinto NM, Kocolas I, Yetman AT. The immediate and long-term impact of pregnancy on aortic growth rate and mortality in women with Marfan syndrome. J Am Coll Cardiol. 2012;60:224-9.

36. Hiratzka LF, Bakris GL, Beckman JA, Bersin RM, Carr VF, Casey DE Jr, et al; American College of Cardiology Foundation/American Heart Association Task Force on Practice Guidelines; American Association for Thoracic Surgery; American College of Radiology; American Stroke Association; Society of Cardiovascular Anesthesiologists; Society for Cardiovascular Angiography and Interventions, et al. 2010 ACCF/AHA/ AATS/ACR/ASA/SCA/SCAI/SIR/STS/SVM guidelines for the diagnosis and management of patients with Thoracic Aortic Disease: a report of the American College of Cardiology Foundation/American Heart Association Task Force on Practice Guidelines, American Association for Thoracic Surgery, American College of Radiology, American Stroke Association, Society of Cardiovascular Anesthesiologists, Society 
for Cardiovascular Angiography and Interventions, Society of Interventional Radiology, Society of Thoracic Surgeons, and Society for Vascular Medicine. Circulation. 2010;121:e266-369.

37. Matura LA, Ho VB, Rosing DR, Bondy CA. Aortic dilatation and dissection in Turner syndrome. Circulation. 2007;116:1663-70.

38. Loeys BL, Schwarze U, Holm T, Callewaert BL, Thomas GH, Pannu H, et al. Aneurysm syndromes caused by mutations in the TGF-beta receptor. N Engl J Med. 2006;355:788-98.

39. Thorne SA. Pregnancy in heart disease. Heart. 2004;90:450-6.

40. Spits C, De Rycke M, Verpoest W, Lissens W, Van Steirteghem A, Liebaers I, et al. Preimplantation genetic diagnosis for Marfan syndrome. Fertil Steril. 2006;86:310-20.

41. Jelin AC, Vora N. Whole exome sequencing: applications in prenatal genetics. Obstet Gynecol Clin North Am. 2018;45:69-81.

42. Thorne S, MacGregor A, Nelson-Piercy C. Risks of contraception and pregnancy in heart disease. Heart. 2006;92:1520-5.

43. Shores J, Berger KR, Murphy EA, Pyeritz RE. Progression of aortic dilatation and the benefit of long-term beta-adrenergic blockade in Marfan's syndrome. N Engl J Med. 1994;330:1335-41.

44. Ong KT, Perdu J, De Backer J, Bozec E, Collignon P, Emmerich J, et al. Effect of celiprolol on prevention of cardiovascular events in vascular Ehlers-Danlos syndrome: a prospective randomised, open, blinded-endpoints trial. Lancet. 2010;376:1476-84.

45. Gandhi SD, Iqbal Z, Markan S, Almassi GH, Pagel PS. Massive retrograde acute type B aortic dissection in a postpartum woman with a family history of Marfan syndrome. J Clin Anesth. 2008;20:50-3.

46. Lind J, Wallenburg HC. The Marfan syndrome and pregnancy: a retrospective study in a Dutch population. Eur J Obstet Gynecol Reprod Biol. 2001;98:28-35.

47. Balsam LB, DeAnda A Jr. Double the jeopardy: balancing maternal and fetal risk during cardiac surgery. J Thorac Cardiovasc Surg. 2015;149:611-2.

48. Gelpi G, Pettinari M, Lemma M, Mangini A, Vanelli P, Antona C. Should pregnancy be considered a risk factor for aortic dissection? Two cases of acute aortic dissection following cesarean section in non-Marfan nor bicuspid aortic valve patients. J Cardiovasc Surg (Torino). 2008;49:389-91.

49. Collins D. Aetiology and management of acute cardiac tamponade. Crit Care Resusc. 2004;6:54-8.

50. Gupta A, Umapathi KK, Gupta M. Fetal outcomes after cardiac surgery during pregnancy: a meta-analysis. JACC. 2020;75:2123.

51. Ch'ng SL, Cochrane AD, Goldstein J, Smith JA. Stanford type A aortic dissection in pregnancy: a diagnostic and management challenge. Heart Lung Circ. 2013;22:12-8.

52. Smok DA. Aortopathy in pregnancy. Semin Perinatol. 2014;38:295-303.

53. Preventza O, Coselli JS. In pregnancy, aortic tissue is the issue. J Thorac Cardiovasc Surg. 2017;153-160.e1. 